\title{
GERDA WEGENER (1885-1940), UNA DANESA EN PARÍS: RETRATOS DE UNA PAREJA SINGULAR Y CREACIÓN DE UNA IDENTIDAD TRANSGÉNERO ${ }^{1}$
}

Eva María Ramos Frendo

Universidad de Málaga

Data recepción: 2017/01/06

Data aceptación: 2018/03/18

Contacto autora: emramos@uma.es

ORCID: https://orcid.org/0000-0003-3669-3438

\section{RESUMEN}

El objetivo de nuestro ensayo es analizar la actividad como retratista de la danesa Gerda Wegener (1885-1940), cuya trayectoria artística se desarrolla entre Dinamarca, París y Marruecos. Ella fue muy solicitada por artistas y miembros de las altas clases sociales. No obstante, sus retratos más destacados fueron los que mostraron a su esposo, Einar Wegener, bajo el atuendo de su otro yo, Lili Elbe, clara manifestación de las identidades transgénero.

Pero Gerda también trabajó como ilustradora en revistas, anuncios publicitarios y libros, tocó temas satíricos, picantes y de alto contenido erótico. Fue una artista pionera que no dejó indiferente a nadie ante sus creaciones. Hasta el momento era célebre por ser la esposa del primer transexual de la historia y pretendemos que sea su obra la que le de la fama y el reconocimiento que se merece.

Palabras clave: Gerda Wegener, Lili Elbe, retrato transgénero, París, siglo XX

\section{ABSTRACT}

This article analyses the portrait work of the Danish artist Gerda Wegener (1885-1940), who spent her career in Denmark, Paris and Morocco. She was much sought-after among her fellow artists and the members of high society, though the subject of her most outstanding portraits was her husband, Einar Wegener, in his female persona Lili Elbe, a clear manifestation of transgender identities.

Gerda also worked as an illustrator, producing materials for magazines, advertisements and books and exploring satirical and risqué themes with a high erotic content. Ahead of her time, her work invariably aroused strong opinions. Up until now, her fame has come solely as a result of being the wife of the first known recipient of gender-reassignment surgery. It is our aim to address that and for her to be afforded the fame and recognition she deserves for her artistic output.

Keywords: Gerda Wegener, Lili Elbe, transgender portrait, Paris, 20th century

Gerda Wegener, pintora e ilustradora, danesa de nacimiento pero francesa de adopción, desarrolló su carreara artística a lo largo de las primeras décadas del siglo XX. Se trató de una mujer con gran iniciativa, transgresora, polémica y pionera en su época, que aceptó y apoyó a su pareja en su cambio de sexo. De hecho, gracias a ella -como podremos comprobar- su esposo pudo presentarse ante el mundo tal y como deseaba ser visto, bajo una apariencia de mujer. Gerda no contó con el respaldo de su país de origen, posiblemente por no verse con buenos ojos su carácter liberal y 


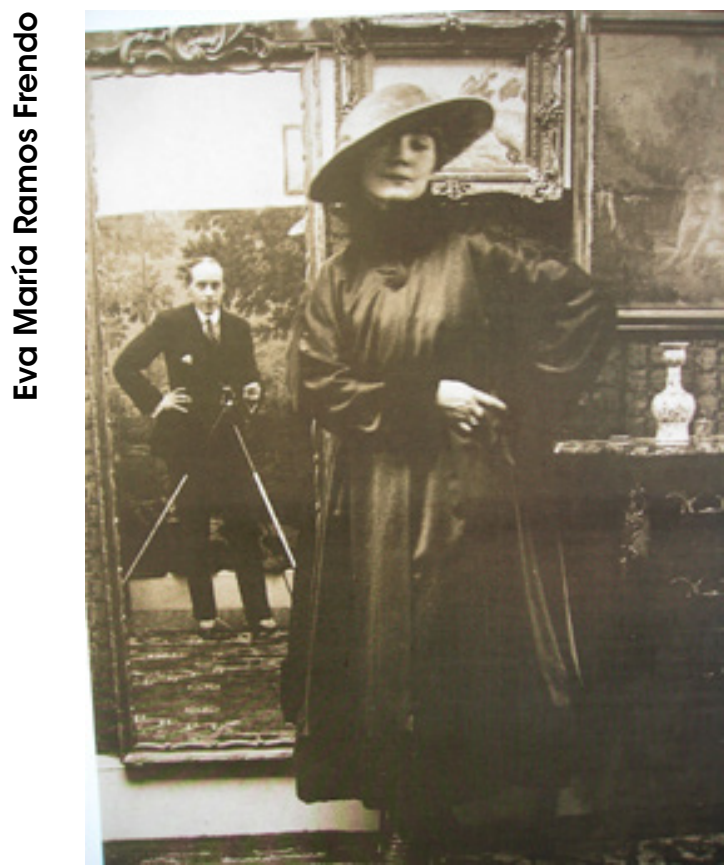

Fig. 1. Gerda Wegener y Einar Wegener en el estudio de París en 1917. Fotografía realizada por Einar Wegener. Colección privada. Gerda Wegener, ARKEN, 2015, p. 8. Copyright ARKEN

la peculiar relación de pareja que mantenía con su marido, el también pintor Einar Wegener (fig. 1), más tarde conocido como Lili Elbe, tras su reasignación de género. Sin embargo, la capital parisina la acogió con los brazos abiertos, cuando se trasladaron en 1912. Allí adquirió una gran fama, constatada por los numerosos encargos que recibió para ilustrar revistas, libros, crear la imagen de firmas publicitarias y realizar retratos, aspecto este último objeto de análisis y estudio del presente trabajo. Ella se fue introduciendo en un mundo en el que la mujer apenas había estado presente y comenzó a abordar temáticas inusuales para su género -como la plasmación totalmente explícita de relaciones lésbicas o la imagen transexual de su pareja- lo que provocó, seguramente, salvo en los ambientes más bohemios, polémicas reacciones.

Por ello, queremos centrarnos en sus retratos que nos sirven de vehículo para acercarnos a su propia vida, al círculo de amistades que la rodearon y que permitieron a su pareja, Lili, la construcción de una nueva identidad de género para mostrarse a la sociedad tal y como quería y necesitaba ser vista. Es, precisamente, esa plasmación y difusión de la imagen de la primera mujer transexual de la historia, esa imagen transgénero, lo que constituye la principal aportación de Gerda al mundo del retrato. Con ella se visibiliza un colectivo silenciado y se muestra desde el respeto, libre de cualquier tratamiento irónico o satírico, plasmándolo con la elegancia y feminidad que le corresponde.

\section{Breve recorrido por su vida y trayectoria artística $^{2}$}

Gerda Wegener, en realidad Gerda Marie Frederikke Gottlieb, nació el 15 de marzo de 1885³ en Hammelev del municipio de Haderslev al sur de Dinamarca. En 1902 se traslada a Copenhague para estudiar en la Escuela para Mujeres de la Real Academia Danesa de Bellas Artes, donde permaneció hasta 1905. Allí coincidió con Einar Wegener, pintor de paisajes, con el que contrajo matrimonio en 1904.

Gerda comenzó a participar en las exposiciones de su país, desde 1904 hasta 1909, (Charlottenborg Spring Exhibition, Autum Art Exhibition y The Journalists' Association's Union). No obstante, en 1907, es protagonista de un controvertido episodio que provocó división de opiniones en el mundo artístico danés, a raíz de ser rechazado uno de sus retratos - Ellen von Kohl, 1906 -, por la Charlottenborg Exhibition y el Salón des Independents. El cuadro sería calificado como un plagio del Manierismo italiano y de los Prerrafaelistas ingleses. Este hecho fue totalmente censurado y denunciado por otro artista danés, Gudmund Hentz, que defendió la obra de la artista y la incluyó dentro del círculo de pintores del Simbolismo, atacando por el contrario a los pintores del Realismo. Las opiniones vertidas provocaron la respuesta de otros artistas y críticos como Peter Hanseno, Karl Madsen o Agnes y Harald SlottMoller. El periódico danés Politiken fue el escenario en el que se desarrolló este enfrentamiento entre defensores del Realismo y del Simbolismo respectivamente ${ }^{4}$. Mientras tanto, Gerda se mantuvo totalmente al margen de la polémica.

En 1908 y 1909 vio recompensados sus esfuerzos al alzarse como ganadora en sendos concursos promovidos por el diario Politiken con 
sus obras Conpenhagen Woman y Figures of the Street, donde se observa a los actores Stellan Rye y Anna Larssen. A partir de estos premios comenzó a colaborar en dicho periódico y, en años posteriores, también con otras revistas danesas como Klods-Hans, Tik Tak, Berlingske Sondag o Vore Damer. Pero, sobre todo, fueron fundamentales para lanzar su carrera en Dinamarca los retratos que realizó del director de cine Stellan Rye y de la actriz Anne Larssen (1906 y 1908). Igualmente, sus postales de temáticas diversas le dieron una gran fama, advirtiéndose en algunas de ellas la influencia del estilo de Aubrey Beardsley. La buena crítica de sus dibujos, a partir de una exposición en Ole Haslunds Hus, la animo a iniciar su carrera internacional.

En 1912 el matrimonio se trasladó a París donde, desde 1889 a raíz de la Exposición Universal, existía una destacada colonia de artistas nórdicos, en torno al barrio de Montparnasse, que se habían establecido en la ciudad considerada como el centro del Arte. Desde entonces la presencia de este círculo se hizo habitual en los diferentes salones y exposiciones de París: Salón de los Independientes, Salón de la Sociedad Nacional de Bellas Artes, Salón de Otoño, Salón de Humoristas o Salón d'Antin, entre otros ${ }^{5}$. La pareja, desde 1917, se estableció en el $n^{\circ} 33$ del Campo de Marte de París, cerca de la Torre Eiffel y formaron parte del grupo de artistas - pintores, escultores, músicos, poetas, etc. - que se reunían en los locales del barrio de Montparnasse: Le Dôme, La Rotonde y La Coupole.

Poco después de afincarse en París, Gerda comenzó a colaborar como artista gráfica en revistas de moda y satíricas, como Journal des Dames, Fantasio, La Baïonette, Le Sourire de France, La Vie Parisienne y Femina?. Esta actividad colocó su nombre junto a los ilustradores más destacados del Art Déco como George Barbier, Charles Martin o Umberto Brunelleschi, entre otros. Su faceta como humorista - algo en lo que también se incluyó otra mujer, Helen Dryden - fue vista con extrañeza por la crítica. Así el español José Francés expuso que la consideraba una actividad poco habitual para las mujeres pues requería de una gran serenidad, rebeldía y reflexión, algo que, por tanto, debía pensar no era propio ni habitual en el género femenino. Sus imágenes más modernas dejaron también constancia de las nuevas modas en alta costura, siendo descritas sus ilustraciones como imágenes mágicas ${ }^{9}$. Sus creaciones fueron igualmente destinadas al diseño de mobiliario, vidrieras y otros espacios de las viviendas para las familias más pudientes y sofisticadas del París de la época, como se puede apreciar a través de la prensa que, en 1929, aludió a una piscina en gres rosa decorada con unos deliciosos frescos de Gerda Wegener ${ }^{10} \mathrm{o}$ las vidrieras para escaparates de tiendas parisinas como L'Acropole (1925) o Leinen-Peuch (1923)"1. Esta actividad le fue reconocida con la obtención de medallas, una de bronce y dos de oro, en la Exposición Internacional de Artes Decorativas e Industriales Modernas celebrada en París en 1925.

Durante la Primera Guerra Mundial, Gerda destacó como ilustradora satírica con imágenes sobre dicho conflicto bélico. De hecho, pronto la crítica de arte se hizo eco de esta faceta de la artista por ser tan inusual en las de su sexo y exaltaron el gran dominio que demostraba en el dibujo y color. Nuevamente José Francés, en relación a Gerda, diría: "No es frecuente el caso de una mujer caricaturista, en la amplia y verdadera significación del vocablo. Tan poco frecuente, que al encontrarnos con Gerda Wegener, queremos recordar precedentes y los precedentes no existen"12. Los dibujos que publicó en La Baïonette - en los que demostró su apoyo al bando aliado, exaltando en especial al militar francés y criticando al enemigo alemán - fueron calificados «de una agresividad viril en la intención y de una refinadísima elegancia en la forma» ${ }^{13}$ y Apollinaire, gran admirador de la artista, consideró que sus obras de aliento a Francia en la Gran Guerra la convertían en una parisina más ${ }^{14}$. La artista demostró que no tenía nada que envidiar a los caricaturistas varones, siendo comparados sus trabajos con los del holandés Luis Raemaekers cuyo anti-germanismo le llevó a que pusieran precio a su cabeza.

También, en los años previos al conflicto bélico, Gerda Wegener se relacionó con los artistas, músicos, poetas, etc. de la vanguardia parisina (Fernand Léger, Duchamp-Villon, Raoul Dufy, Marc Chagall, Robert Delaunay, Erik Satie, Valentine de Saint-Point, Apollinaire, etc.) colaborando con la gaceta bimensual de arte Montjoie' ${ }^{15}$, dirigi- 
da por el italiano Ricciotto Canudo, y asistiendo a los denominados "Les Lundis de Montjoie" 16 , encuentros de presentación de obras artísticas, recitales de poemas, audiciones musicales, etc., donde se codeaba con todo el mundo de la bohemia parisina del momento.

Algunas de sus imágenes también fueron destinadas a anuncios publicitarios de marcas como Gyraldose, Arys, Malaceïne, Forvil, etc., todas ellas empresas centradas en la fabricación de productos de perfumería. Además continuó con la realización de retratos de artistas y miembros de la alta sociedad, mientras Einar seguía centrado en los paisajes, su especialidad. Otra faceta a destacar de su trayectoria será la ilustración de un extenso número de libros tales como: L'Abdication de Ris-Orangis (1918) de Léo Larguier; Le Péplôs Vert (1922) de Maurice de Waleffe; Le Libre des Vikings (1924) de Charles Guyot; Amour étrusque (1898) de Joseph Henry Rosny; La Mythologie (1928) de la misma Gerda Wegener; Contes de mon père le Jars (1919) de Eric Allatini; Les délassements d'Eros (1925) de Louis Perceau; Une aventure d'amour à Venise (1927) de Casanova; Sur talons rouges (1929) de Eric Allatini o Fortunio (1934) de Théophile Gautier.

Desde 1913 el nombre de Gerda Wegener ya comienza a aparecer, al igual que el de su esposo, en las exposiciones celebradas en París ${ }^{17}$ y continuarán presentes a lo largo de toda la década de los veinte. A su vez contribuyeron en otras actividades como la decoración, por parte de Einar, de una sala de la ambulancia flotante $L a$ Danoise donada, en 1915, por la colonia danesa a las damas de la Cruz Roja francesa como señal de aprecio para que pudieran atender en ella a los militares heridos. Einar realizó un paisaje con el castillo de Kronborg, ubicado cerca de Elsinor en Dinamarca'18.

Los catálogos del Salón de los Independientes nos permiten hacer un seguimiento de las creaciones de Gerda desde 1921 hasta 1930'19. En marzo de 1923 nos consta la presencia del matrimonio en una exposición exclusiva en la galería de Marcel Bernheim que estaría vigente hasta el 7 de abril de ese año ${ }^{20}$. Los críticos se hicieron eco de la creciente presencia de mujeres en las exposiciones parisinas del Salón de los Humoristas y así, en 1922, se citó a Gerda Wegener junto con otras dos artistas -Charlotte Schaller-Mouillot y Elisabeth Branly- y describieron sus obras como llenas de un gran encanto y dignidad ${ }^{21}$. Además estuvo presente en diversas ocasiones en el Salón de Otoño22, en el Nuevo Salón, ubicado en la Galerie Siot-Decauville ${ }^{23}$, y en el Palais de Marbre, en $1928^{24}$. No abandonó, no obstante, los contactos con su tierra natal, como lo demuestra su presencia en la galería de Copenhague Ole Haslunds Hus a lo largo de diversos años donde ella y su esposo expusieron sus obras. En 1929, Gerda, nuevamente, dejó constancia de sus aportaciones con diseños destinados a las artes decorativas. Ella, junto con otros artistas - Raoul Dufy, Francis Jourdain, Foujita, Marcel Roche, Yvonne Sjoestedt, Dupas y Aronson- participaron en una exposición organizada por el matrimonio formado por el ingeniero Jean Charles y la cantante Speranza Calo Séailles en el Barrio Latino de París. El objetivo de la muestra fue dar a conocer las creaciones realizadas a partir de un nuevo material, descubierto y patentado por Speranza Calo, Le Lap. La inauguración de la exposición estuvo a cargo del Director General de Bellas Artes, Paul Léon ${ }^{25}$. De hecho, en este mismo año, nuevamente la prensa exaltó el destacado papel que jugaban las mujeres dentro de las artes decorativas, citando a Gerda, que era descrita como "la princesa de la línea" ${ }^{26}$ y augurando que sus obras tendrían, en un futuro, un valor inestimable.

En 1929 participó en otro acto para el que, posiblemente, fue escogida por considerarla una experta en crear y detectar la belleza. Se trató de un certamen, celebrado en la sede de Le Journal, al que concurrieron jóvenes de los diferentes países de Europa: Inglaterra, España, Alemania, Francia, Italia, Austria, Bulgaria, Dinamarca, Grecia, Holanda, Hungría, Rusia, Rumanía, Suiza, Yugoslavia, etc. Se escogió un jurado formado por pintores y escultores en su mayoría. Junto a Gerda destacaremos otros nombres como Otto von Watjen, William Ablette, Robert Fix, Beltrán Masses, Galanis, Van Dongen o el conde Zamoyski. Finalmente la representante Húngara se alzó con la victoria ${ }^{27}$.

No sabemos en qué momento se inició el disgusto de Einar con su cuerpo y apariencia y comenzó a sentirse más cómodo adoptando atuendos de mujer. Según las memorias de Einar ${ }^{28}$, fue 
la propia Gerda quien, en cierto modo, incitó a su marido a posar vestido de mujer para ayudarla a finalizar las piernas de un retrato que estaba ejecutando de la actriz danesa Anna Larssen. A lo largo de la década de los veinte se apreció una paulatina desaparición de las obras de Einar en los diversos salones o una presencia más intermitente, conforme se fue acercando la fecha de las operaciones para intentar dotarlo de un cuerpo de mujer. Estas ausencias pueden deberse al padecimiento de una depresión, tal y como manifestó en sus memorias ${ }^{29}$, que le llevaron a un progresivo abandonando de su propia carrera en apoyo a la de su esposa, mientras él se volcaba en las tareas del hogar ${ }^{30}$. Gerda, mientras tanto, se vio muy solicitada, convirtiéndose dentro de la pareja en la que aportaba los mayores ingresos para el sustento de ambos. Finalmente Einar se trasladó a Dresde donde fue examinado por el doctor Kur Warnekros, director de una clínica de dicha ciudad, quien dictaminó que su cuerpo estaba sufriendo una transformación y debía ser intervenido para convertirlo definitivamente en mujer ${ }^{31}$. Tras seis meses de intervenciones acabó el proceso que transformó a Einar definitivamente en una mujer, lo que provocó que el matrimonio fuera considerado nulo por el rey de Dinamarca en octubre de 1930. La prensa, inmediatamente, se hizo eco de la noticia ${ }^{32}$. En el tiempo que transcurrió este proceso de cambio, Einar escribió a sus amigos elogiando a Gerda por estar volcada en trabajar por los dos, a la vez que él se dedicaba a vender obras a Heyman \& Haslund para costear todos los gastos de la operación ${ }^{33}$. Einar pasó desde entonces a llamarse Lili llse Elvenes o Lili Elbe, Lili otorgado por Anne Larssen y Elbe adoptado por su amor hacia el río Elbe que atravesada Dresde, donde había sido intervenida en las últimas ocasiones ${ }^{34}$. En febrero de 1931, Gerda y Lili expusieron juntas en Copenhague en la galería Haslund \& Heyman.

El 2 de marzo de 1931, transcurridos varios meses de la anulación de su matrimonio con Einar, Gerda volvió a casarse con un oficial italiano de las Fuerzas Aéreas, Fernando Porta. Este hecho quedó patente también en la producción de la artista a través de su firma puesto que, hasta ese momento, ella había firmado sus obras como Gerda Wegener y, a partir de este nuevo matrimonio, añadió el apellido Porta. La pareja se trasladó a vivir entre Marraquech y Casablanca en Marruecos. Tras realizar un viaje a Italia, Lili acudió a Dresde para recibir una última intervención quirúrgica por el ya citado doctor Kurt Warnekros con el fin de dotarla de ovarios. A pesar de que la operación resultó un éxito, complicaciones por problemas cardiacos provocaron el fallecimiento de Lili. Dos años después de su muerte, en 1933, Ernst Ludwig Hathorn Jacobson, bajo el pseudónimo de Niels Hoyer, escribió un libro titulado Man Into Woman, sirviéndose de las cartas y diarios del pintor.

En 1934 Gerda participó en una exposición, organizada por la Asociación de Pintores y Escultores de Marruecos ${ }^{35}$, en la que mostró su obra junto a la del también pintor, de origen argelino, Azouaou Mammeri. La Exposición en Marraquech se ubicó en el Hotel de la Mamounia, mientras en Casablanca lo hizo en la Galería Derche. No obstante, ya había mostrado su obra con anterioridad en L'Exposition de Peinture de la Foire de Marrachech donde, junto a retratos con fondos de paisajes marroquíes (Les femmes fatales, PapiIlons o Pareja oriental, todas de 1933), donde ya apreciamos la nueva firma Gerda Wegener Porta, también presentó paisajes, danzas y espacios típicos de Marrachech: Le Bal de la Mamounia, Danseurs Chleuhs o Place Djema-el-Fna, todo de una manera original y decorativa que resultó muy del gusto de los nativos de allís.

En 1936 Gerda se divorció de su segundo esposo y un año más tarde, en 1937, volvió a concurrir al Salón de los Independientes con una obra titulada Eve que la crítica describió como una Eva con pelo de oro y líneas suaves ${ }^{37}$. La pecadora de piel blanquísima se dispuso entre variadas especies de flores, de vivos colores, ubicadas a la orilla de un lago de cisnes, mientras portaba la manzana. La serpiente se convirtió en una simple culebrilla que, a modo de adorno, se enrollaba en uno de sus brazos. Por esta fecha también mostró una joven similar que representaba la Primavera (1938), con un estilo muy Botticelliano, con diadema floral y la compañía de un cupido, iconografía muy habitual en toda su obra. En 1938 regresó a Dinamarca, donde continuó exponiendo hasta 1939, aunque el éxito anterior fue en descenso. Pocos meses después, el 20 de julio, se produjo el fallecimiento de Gerda en Frederik- 
sberg, sola, pobre y olvidada ${ }^{38}$. Hacia la década de los 60 Dinamarca volvió a redescubrir a Gerda y sus obras subieron de precio, reconociéndosele tardíamente el talento especial que tuvo.

\section{Gerda Wegener, retratista de la alta socie- dad y el mundo del espectáculo}

El realizar un análisis de los retratos de Gerda Wegener presenta una gran dificultad, puesto que la gran mayoría de las obras de la artista se encuentran en la actualidad formando parte de colecciones privadas cuyos propietarios no nos son identificados ${ }^{39}$. Los críticos y revistas de la época tampoco se volcaron en hacer un estudio detallado de sus obras, limitándose a citar los títulos que presentaba a los diferentes salones y realizar algún comentario generalizado alabando el estilo de la artista y la belleza y espiritualidad de sus mujeres. Por tanto intentaremos, a través de la visión de las piezas, descubrir quiénes fueron los retratados por Gerda, qué características o motivos se repiten en su obra, las posibles influencias estilísticas y, sobre todo, los mensajes que sobre su vida personal y la de su pareja pueden estar presentes.

Gerda, dentro de la pintura, se especializó en el género del retrato, como se puede apreciar a través de las numerosas obras que hoy nos han llegado y las referencias a las mismas que tenemos en las exposiciones de la época. Tan solo acercarnos a la reciente exposición de Arken nos permite comprobar que, de 169 obras de la artista, 100 son retratos. No obstante, también cultivó escenas de la vida cotidiana - ese París de los años veinte con mujeres modernas -, otros momentos del pasado - como el mundo griego y su mitología, la Edad Media, el siglo XVIII o escenas del mundo bíblico - y, aunque de forma más escasa, el bodegón y el paisaje.

Un recorrido por sus retratos nos permite apreciar lo solicitada que fue la artista, tanto por miembros de las clases elevadas como, sobre todo, por figuras del mundo del arte, el diseño, la danza y el cine del momento, en especial daneses, muchos de ellos amigos personales del matrimonio Wegener: las actrices Oda Nielsen, Anna Larssen y Karin Nellemose; las bailarinas Ulla Poulsen, Carina Ari o Ellen Tegner; ilustradores como Maggi Baaring o Sven Brasch; el di-

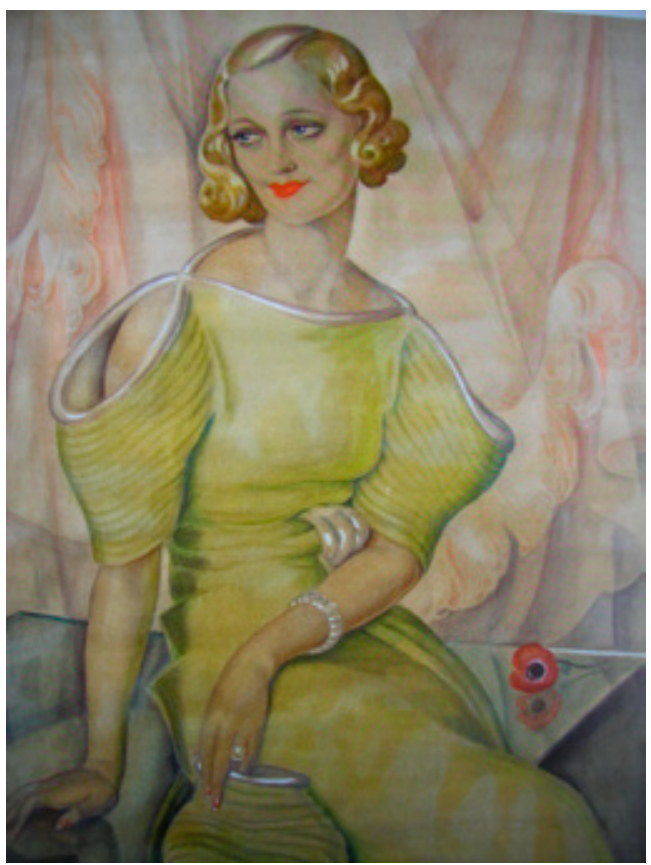

Fig. 2. Eva Heramb, 1934, Gerda Wegener, dibujo y acuarela sobre papel $(100 \times 77,5 \mathrm{~cm}$.). The Theatre Museum at The Court Theatre. En Gerda Wegener, ARKEN, 2015, p. 79. Copyright ARKEN

señador y escenógrafo Max Rée; la pintora Elna Tegner, esposa del escultor Rudolf Tegner; o el periodista y editor Helge Wamberg con su esposa Sascha, entre otros. Gerda comenzó visibilizando a lo más destacado de la Dinamarca de su época y los encargos prosiguieron a partir de su establecimiento en París, donde mantuvo el contacto con miembros de la colonia danesa allí afincados o de paso.

Aunque retrató a hombres - como en 1930 al mismo doctor alemán Kurt Warnekros que intervendría quirúrgicamente a Lili - lo que le dio la fama fue ser la artista que supo representar "... de forma única la belleza de las mujeres" ${ }^{40}$. Sus obras muestran siempre a damas elegantes, dulces, espirituales -así eran descritas por los críticos ${ }^{41}$ - apelativos que también otorgaron a las mujeres pintadas por Tamara Lempicka, inserta en el mismo estilo que Gerda, el Art Déco, y con la que coincidió en diversas exposiciones. Pero en el caso de la polaca, el aspecto de sus modelos, también miembros de la élite parisina de los años veinte y treinta, resulta mucho más escultórico, 


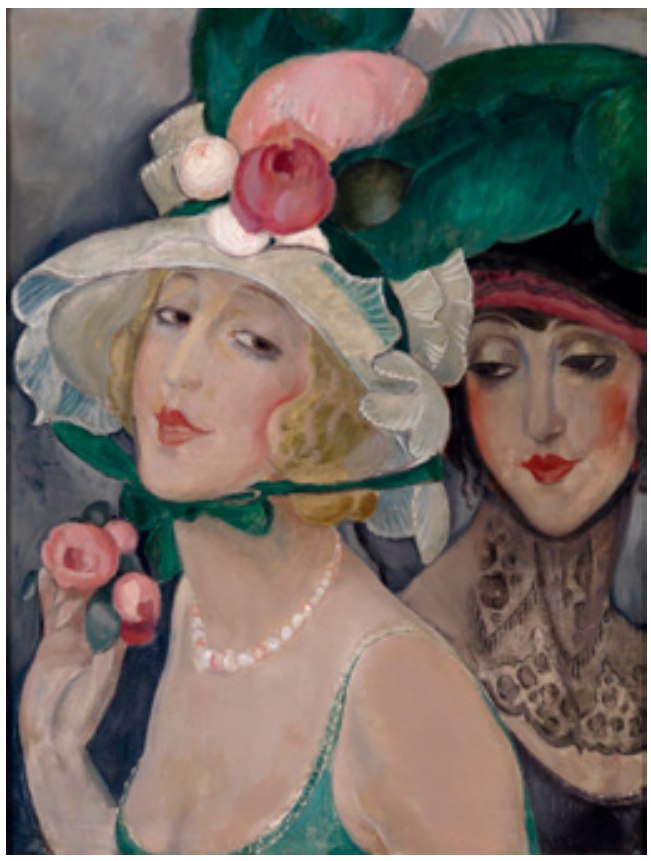

Fig. 3. Two Cocottes in Hats (Lili and friend), 1920, Gerda Wegener, pintura al óleo $(61 \times 45 \mathrm{~cm}$.), propiedad de Anne Ammitzbol. En Gerda Wegener, ARKEN, 2015, p. 12. Copyright ARKEN

anguloso y frío, con pinceladas más pulidas y generando unos planos mucho más cercanos en los retratos. A su vez, los fondos geométricos dentro del cubismo sintético que reflejan la moderna urbe en Lempicka, con sus grandiosos rascacielos, se sustituyen por paisajes ocres y verdosos, de una modernidad menos acusada en Gerda, recordando en ocasiones a Picasso y Braque en su etapa de Horta de Ebro (Madonna and Child with Angels Making Music de 1935 u Oriental Couple de 1930, entre otras). Gerda, cuando retrató a las damas de la alta sociedad las ubicó, mayormente, en interiores domésticos con un mobiliario más decimonónico, alejado de la modernidad de los entornos de su coetánea. Tan solo alguna de sus últimas obras nos traen ligeros recuerdos de las mujeres de Tamara Lempicka - como el retrato de la actriz danesa, Eva Heramb de 1934 (fig. 2) - pero sin llegar a la dureza extrema de la polaca. Esa modernidad-como expondremos- también se advertirá en algunos retratos de ella y Lili.

Una constante en los retratos femeninos de Gerda será la presencia de flores, elemento tam-

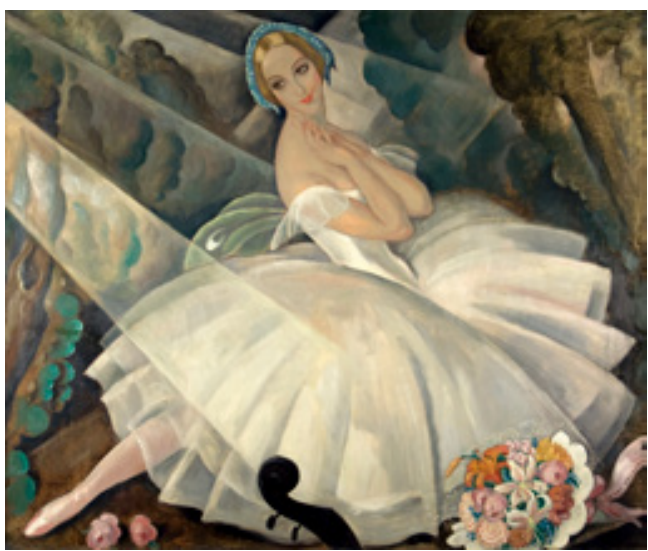

Fig. 4. The Ballerina Ulla Poulsen in the Ballet Chopiniana, 1927, Gerda Wegener. The Theatre Museum at The Court Theatre. En http://www.arken.dk/presse/gerda-wegener/. Copyright ARKEN

bién presente en los títulos de sus obras como Femme a la Rose, presentada al Salón de Otoño de $1928^{42}$. En algunos casos esas flores aportaban simbolismo o mensajes, como en Two Cocottes with Hats (fig. 3), donde Lili sostiene una rosa que es interpretada como símbolo de aquello a lo que aspira, la feminidad ${ }^{43}$. Además de disponer flores en las manos de las retratadas - Karen Kal Clausen, 1923 - en otras ocasiones ornamentan sus cabellos, los sombreros o sirven de motivo decorativo a las tapicerías del mobiliario - Brigitte Bergman, 1920 o La Sophistiquette, 1929. En la mayoría de estos retratos femeninos los ropajes presentan tonalidades claras: blancos o rosáceos, salvo alguna excepción. Todas las retratadas son mujeres elegantes y demuestran, por su porte, sus vestidos, sus joyas y el entorno en que se ubican, su pertenencia a clases pudientes. Las dispone habitualmente sentadas, salvo algunas excepciones, como el retrato de Lilian Lauritzen, de 1924, donde la retratada se presenta en pie ante un tapiz, otro objeto de lujo.

Coetánea a Gerda será la artista Maurie Laurencien que compartirá con ella los mismos ambientes, actividades y espacios expositivos y, además, plasmará también un mundo femenino plagado de jóvenes etéreas y elegantes, entre las que sobresalen nombres como la diseñadora Coco Chanel, la empresaria y coleccionista de arte Helena Rubinstein o la novelista, periodista y artista de revista y cabaré Colette, entre otras ${ }^{44}$. 
Junto a las damas de la alta sociedad, también las pertenecientes al mundo del espectáculo - actrices, bailarinas, etc. - posaron para Gerda. Una de las más destacadas, plasmada hasta siete veces, fue la bailarina danesa Ulla Poulsen a su paso por París en gira con el Teatro Real danés por Europa y Estados Unidos. En el retrato ejecutado en 1927 (fig. 4) nos la muestra en una de sus actuaciones en el Ballet Chopiniana, justo en el momento de recibir los agasajos y ovaciones del público a través de ramos de flores que caen al escenario. El fragmento del mástil de un contrabajo, dejando ver las clavijas y volutas, al modo de las obras de Degas, nos indica la orquesta ubicada bajo la escena. La joven, con su vaporosa vestido blanco de tul - muy similar al que presenta en fotografías de años después, como la que en 1936 nos la muestra en la representación de La Sylfide - se dispone ante un telón paisajístico, mientras unos rayos luminosos radiantes, tan propios del lenguaje Art Déco, caen sobre ella desde el ángulo superior izquierdo del lienzo, generando formas geométricas y cristalinas que simulan la iluminación eléctrica. Se trata de un recurso muy utilizado en sus obras y que denota la incidencia del lenguaje vanguardista (Futurismo, Cubismo, etc.). De Ulla realizó otros retratos en los que ya la artista se ubicó fuera del ámbito artístico, siendo plasmada igual que el resto de damas elegantes. Volverá años después, 1930 y 1934, a retratarla, lo que nos indica la estrecha relación entre ambas artistas y el aprecio que Ulla tenía hacia la belleza con que era capaz de representar Gerda a las mujeres, dulces, ensoñadoras, seductoras y elegantes.

Otra bailarina, en este caso sueca, Carina Ari que hacia los años 20 estuvo realizando una gira por París - contactó también con Gerda para ser retratada. De ella se cuenta con dos acuarelas, una nos muestra el rostro de la joven con el pelo recogido en moño bajo y alargados pendientes, mientras en otra nos la sitúa en el momento de una de sus actuaciones, ataviada a la española, con peineta y mantón. En ambos casos la similitud con algunas fotografías de la artista es indudable ${ }^{45}$.

Junto a los retratos individuales, podemos encontrar otros de parejas - Pareja oriental (19311934) de su etapa marroquí - o de grupos, en

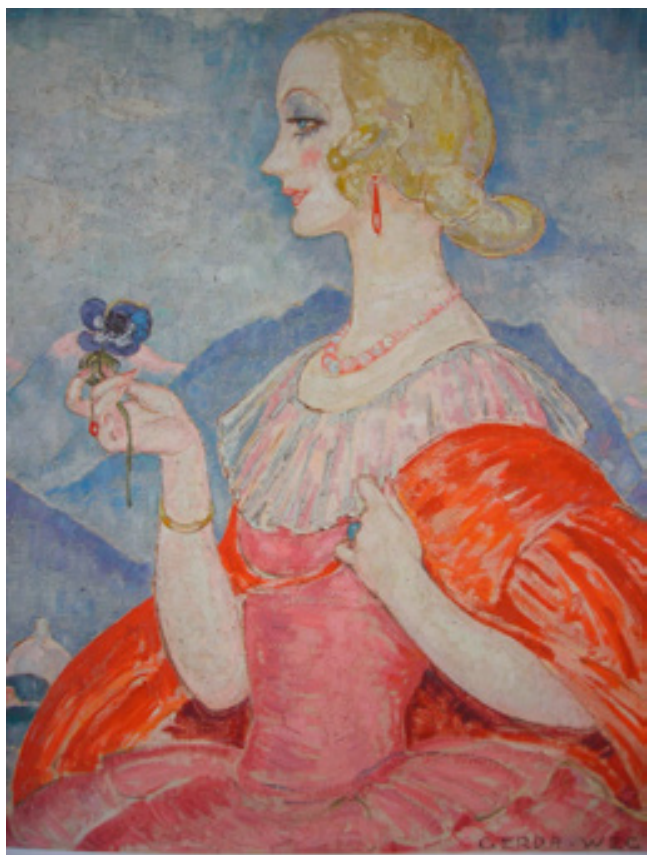

Fig. 5. La dame à l'anémone, 1922, Gerda Wegener, pintura al óleo, 81,8 x 81,5 cm. Centro Pompidou, National Museum of Modern Art. En Gerda Wegener, ARKEN, 2015, p. 23. Copyright ARKEN

especial de mujeres. De los grupos de damas elegantes, muy maquilladas y con miradas de ensoñación, llenas de dulzura, podemos destacar obras como Les femmes fatales o Butterflies, ambas de 1933, realizadas durante el tiempo de residencia en Marraquech, o Femme a la Rose, de 1928. No obstante, en algunos casos, el rostro nos sugiere otras sensaciones, como el busto frontal de la soprano Madame Marcelle Gérar (1923), dispuesto ante un tapiz persa, cuya mirada fue calificada de intrigante ${ }^{46}$. Esta obra, concretamente, se convertirá en 1924 en imagen de uno de los anuncios publicitarios de la empresa de fabricación de sedas Cheney Brothers Silk. Con esta pieza de Gerda la empresa intentaría demostrar que las mujeres estilosas y muy femeninas, que siguen la moda francesa, utilizan las sedas Cheney ${ }^{47}$.

\section{Gerda y Lili: visiones de una vida y una nueva identidad}

Gerda, posiblemente por propio deseo, realizó numerosos retratos en los que se mostraba a 


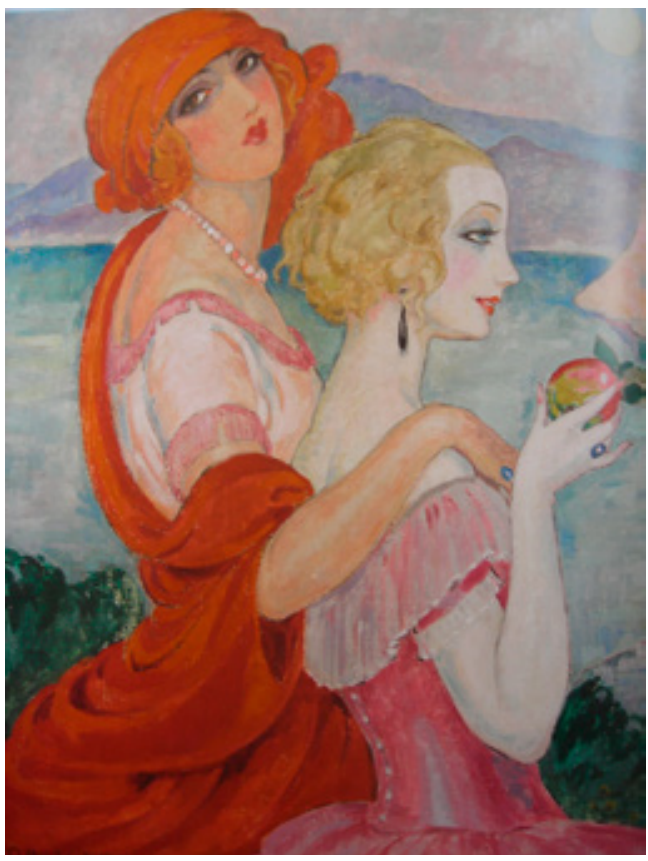

Fig. 6. On the Ways to Anacapri (Gerda and Lili), 1922, Gerda Wegener, pintura al óleo, $96 \times 85 \mathrm{~cm}$. Colección privada. En Gerda Wegener, ARKEN, 2015, p. 22. Copyright ARKEN

sí misma, sola o acompañada de su pareja, Lili, dando la sensación de mostrarnos a dos amigas, tal y como rezaría en algunos de los títulos. Las obras que mostraron a Lili fueron las que supusieron una verdadera revolución en su época al dar paso a la visibilización de personas transgénero.

Uno de los autorretratos de Gerda - que hoy día forma parte de los fondos del Centre Pompidou de París - fue La dame à l'anémone (1922) (fig. 5), considerado una idealización de su propio rostro ${ }^{48}$. Esto queda evidenciado a través del idéntico aspecto y atuendo que presenta en otra obra donde ella y Lili pasean por Capri (fig. 6), la isla italiana donde la pareja pasó numerosos veranos $^{49}$. Al año siguiente, este autorretrato de Gerda fue presentado al Salón de los Independientes $^{50}$. La retratada, de larguísimo cuello y dorados cabellos, se dispone de perfil ante un fondo de paisaje de colores pasteles y gruesas y alargadas pinceladas, en el que predominan las gamas de azules. La joven de blanca piel - como será habitual en la obra de Gerda - va ataviada con un vaporoso y rosado vestido, mientras abriga sus hombros con una capa rojiza que conjunta con el

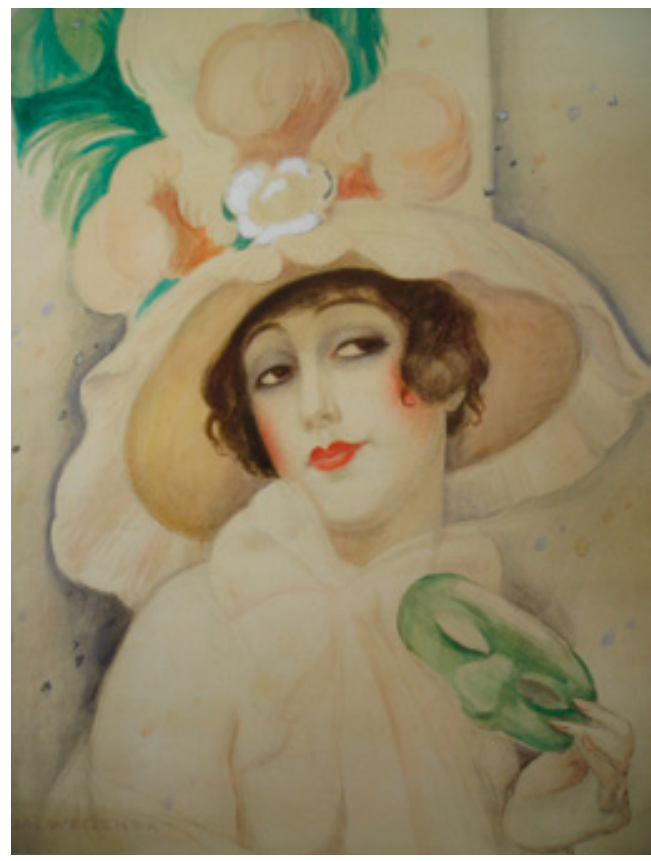

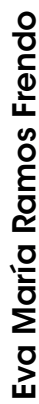

Fig. 7. Carnival, Lily, 1928, Gerda Wegener, dibujo y acuarela sobre papel, $82 \times 55 \mathrm{~cm}$. Colección privada. En Gerda Wegener, ARKEN, 2015, p. 18. Copyright ARKEN

resto de joyas que la complementan y porta la flor que da título a la obra. Se trata de un óleo sobre lienzo que nos trae recuerdos, por la disposición de perfil de la joven con el fondo de paisaje, a los inicios del género en el Renacimiento, como el Diptico de los duques de Urbino (1472) de Piero della Francesca.

Si en ocasiones se muestra acompañada de Lili, mucho más abundantes fueron los retratos en los que plasmó a Lili sola, siendo estas obras las que más fama le han reportado, permitiéndonos considerar a Gerda como una temprana difusora de las imágenes transgénero, Nos consta que, a partir de 1920, Gerda comienza a reflejar a su pareja con su nuevo aspecto femenino. Lili sería su verdadero yo, un disfraz que le permitía mostrarse como realmente se sentía, una imagen que le hacía posible desenmascararse de ese cuerpo y aspecto con el que no se veía identificada. Quizás esas reflexiones sobre la situación de su esposo y la necesidad de un disfraz para, en ocasiones, sacar a relucir su verdadera persona, fuera una de las razones que llevó a Gerda a tratar, a lo largo de su producción, el tema de los carnavales o la 
presencia de las máscaras en los retratos. Esto lo podemos advertir en La belle masque (1922) donde una desnuda joven, dispuesta entre cortinas ornamentadas con rosas, consideradas símbolo de la feminidad, porta una oscura máscara. Esto se repite en el retrato titulado Carnival, Lily (1928) (fig. 7) e, igualmente, en 1922, en Carnival at Magic City (1922) donde observamos un mundo de apariencia y sueños en el que Lili y Gerda flotan por los aires a lomo de un cerdo volador. Puede ser una alusión a ese mundo de disfraz en el que ha entrado Lili, al modo de los carnavales, y en el que la posibilidad de hacer realidad los sueños se lo debe a la pareja que la acompaña, Gerda.

A lo largo de una década Lili aparecerá con muy diferentes aspectos, fruto del uso de variadas pelucas. En 1925, Lili se dispone junto a una ventana, portando un abanico y con un recogido que nos recuerda al que utilizó en el retrato de la bailarina Carina Ari por esas mismas fechas. En otros retratos Lili se muestra con cabellos más cortos y, a veces, en posturas un poco indecorosas. Así, en Queen of Hearts (Lili) (1928) (fig. 8) aparece fumando -hábito que se generalizó entre las mujeres en este periodo como símbolo de modernidad- y calzando zapatos Mary Jane - modelo habitual en las mujeres de esta época - mientras nos permite observar parte de sus piernas y las enaguas interiores. El bodegón de la mesa vuelve a ser un recuerdo del mundo cubista, con los periódicos tan habituales en este género. Esta postura adoptada por Lili resulta provocadora, mirando de manera sensual al espectador que presencia la escena. Aquí Lili se muestra con seguridad y deja atrás las posturas más recatadas y elegantes.

Mucho más temprana es la obra Lili with a Feather Fan, 1920 (fig. 9), donde posa casi de espaldas ante un floral y exótico fondo - posiblemente un tapiz - presentándose ahora como una joven rubia que dispone su cabello en un alto recogido y lleva un vestido entallado en la cintura, guantes, joyas y un plumero, elemento destacado en el título de la obra.

Poco después, en 1922, contamos con un retrato en el que se nos exhibe con cabellos oscuros y cortos, ataviada con diversas joyas, y dispuesta ante unos fondos de paisajes que, con gran probabilidad, deben ser cuadros realizados por

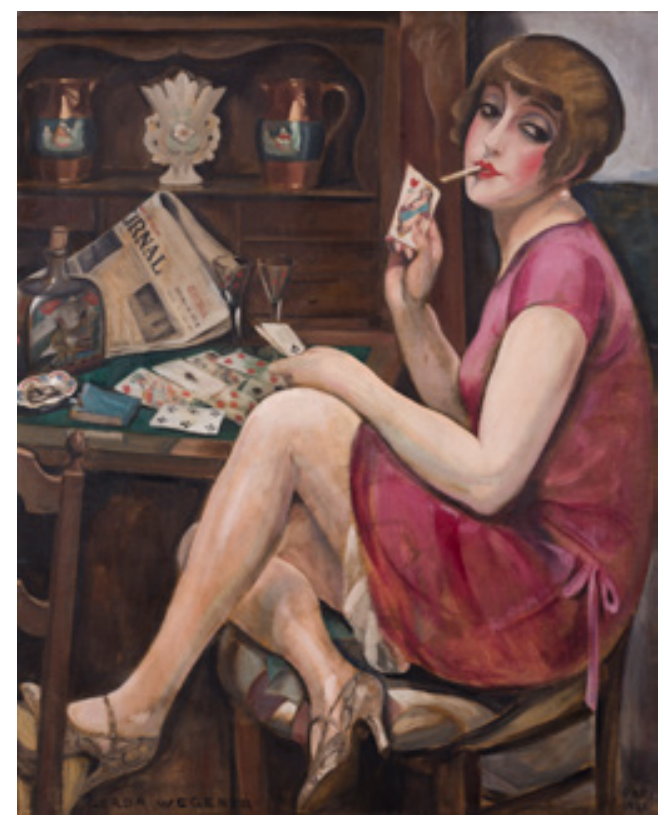

Fig. 8. Queen of Hearts (Lili), 1928, Gerda Wegener, pintura al óleo, $100 \times 81 \mathrm{~cm}$. Colección privada. En Gerda Wegener, ARKEN, 2015, p. 6. Copyright ARKEN

la misma Lili (fig. 10). En la parte superior, con gran tamaño, vemos una obra que parece estar enmarcada y colgada, frente a otros fragmentos en la parte inferior, que deben ser paisajes de la artista dispuestos amontonados junto a la pared, lo que nos hace pensar que nos encontramos en el estudio donde trabajaba la pareja en su domicilio parisino. Estamos viendo, a la vez, la labor de Einar como creador artístico a través de sus obras, mientras como Lili se convierte en objeto de la misma. Este retrato es un reflejo de la doble condición de Einar/Lili, esa dualidad que, en estos momentos, se encontraba viviendo. Aunque se sentía como Lili, a la hora de exponer sus paisajes debía figura bajo su nombre de Einar Wegener.

La duda se nos plantea ante una obra titulada La belle aux bas et escarpins rouge ${ }^{51}$, de 1922, en la que observamos una joven de espaldas, ubicada en un sofá, ante un fondo con motivos orientales. Se trata de un desvestido, más que un desnudo, pues la retratada conserva los zapatos de tacón rojos, que dan título a la obra, a juego con la peineta de igual color que remata el recogido de su pelo, medias rosáceas y un collar de perlas en el cuello. El rostro se vuelve ligeramente hacia 


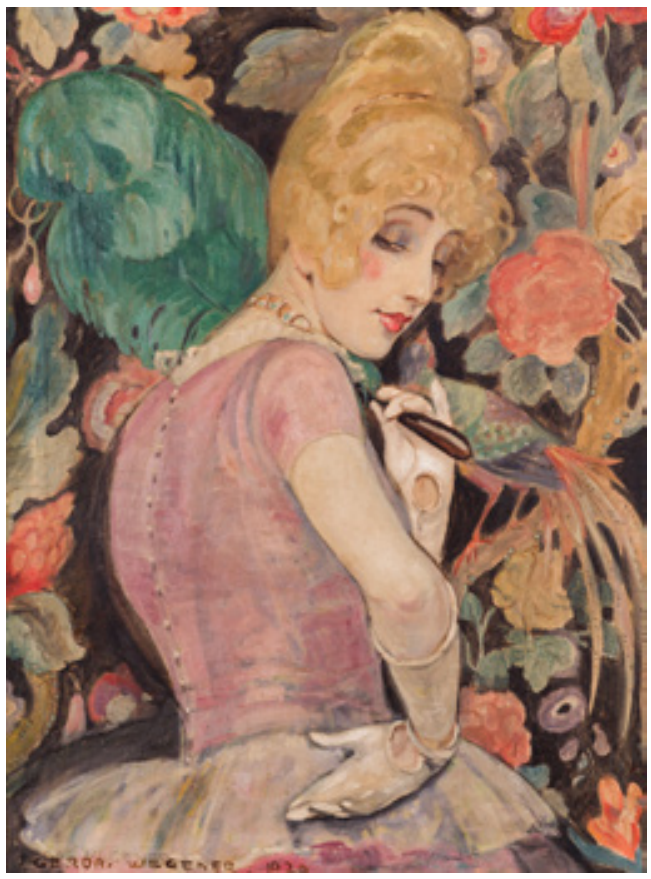

Fig. 9. Lili with a Feather Fan, 1920, Gerda Wegener, pintura al óleo, 79 × $59 \mathrm{~cm}$. Colección privada. En Gerda Wegener, ARKEN, 2015, p. 40. Copyright ARKEN

el espectador y es aquí donde apreciamos un cierto parecido con los otros retratos de Lili, mas su nombre no se hace visible en el título de la obra. No obstante, juega nuevamente al desnudo de espaldas para ocultar la verdadera fisonomía de Lili. En otra pieza, In the Summer Heat (Lili) (1924) (fig. 11), vuelve a disponerla en idéntica postura, al modo de las odaliscas de Ingres, jugando así con la ambigüedad del personaje que, en esta ocasión, se dispone sobre un sillón barroquizante y de tapizado rojo y floral, que hace destacar aún más la piel blanca de la retratada que porta un abanico para aliviar la sofocante temperatura que el título describe. Idéntico abanico al del cuadro podemos observar en una fotografía de Lili, la cual se presenta ante un fondo ornamentado similar al que aparecía en sus retratos (fig. 12).

El Centre Pompidou de París cuenta también con dos retratos de Lili, ambos realizado en 1922. Uno de ellos, The Siesta (1922)52 (fig. 13), nos muestra a Lili recostada entre las sábanas y sosteniendo en una de sus manos la novela Les Liaisons dangereuses (1782) de Pierre Choderlos de Laclos. Indiscutiblemente, no es casual la presen-

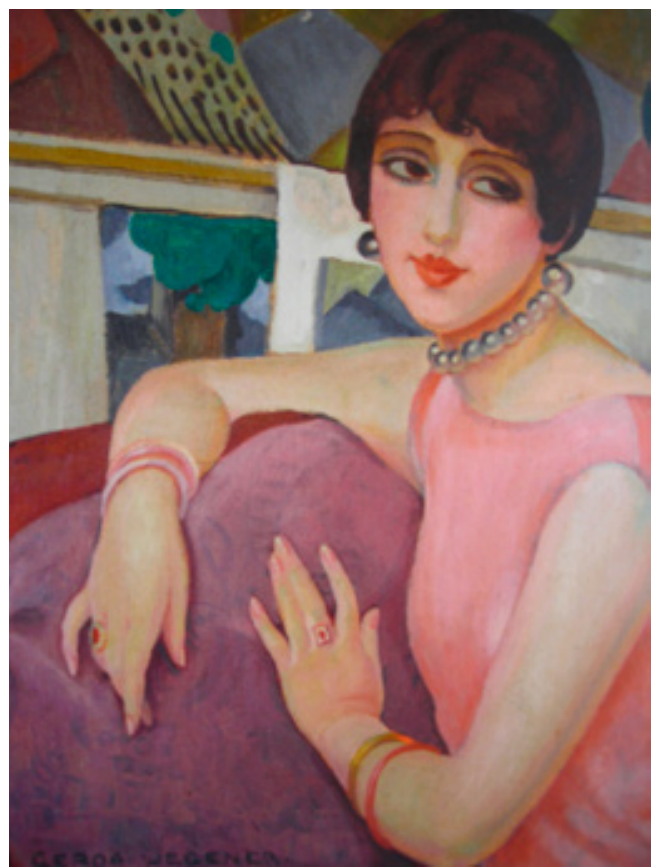

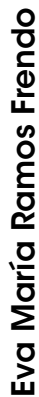

Fig. 10. Lili, 1922, Gerda Wegener, pintura al óleo, 73,2 x 60 cm. Colección privada. En Gerda Wegener, ARKEN, 2015, p. 73. Copyright ARKEN

cia de la novela en el retrato, cuyo título nos deja observar con total claridad. La novela nos refleja en el relato a la Marquesa de Merteuil, obligada a disimular su vida licenciosa por su condición de mujer, viuda y marquesa, ante una sociedad puritana en la que, lo que es bien visto y agasajado en el hombre, el ser un libertino, es condenado en las mujeres. Lili se debió sentir identificada con la historia y situación de la marquesa pues, como ella, su vida fue un continuo juego de disimulo, en su caso para ocultar una condición sexual con la que no se sentía identificada, en una sociedad que, del mismo modo, tampoco se encontraba preparada para su transformación. Gerda nos muestra a Lili reflexiva y pensativa, marcando con el dedo la página de la novela en la que ha detenido su lectura.

Además de las imágenes en solitario, otras muestran a Lili acompañada de su esposa o de otras mujeres. Ante la visión del espectador se hace difícil evidenciar la existencia de dos géneros diferentes en las imágenes. Ambas, Gerda y Lili, se nos muestran altamente femeninas y siempre en perfecta comunión. Estas obras reflejan lo que 


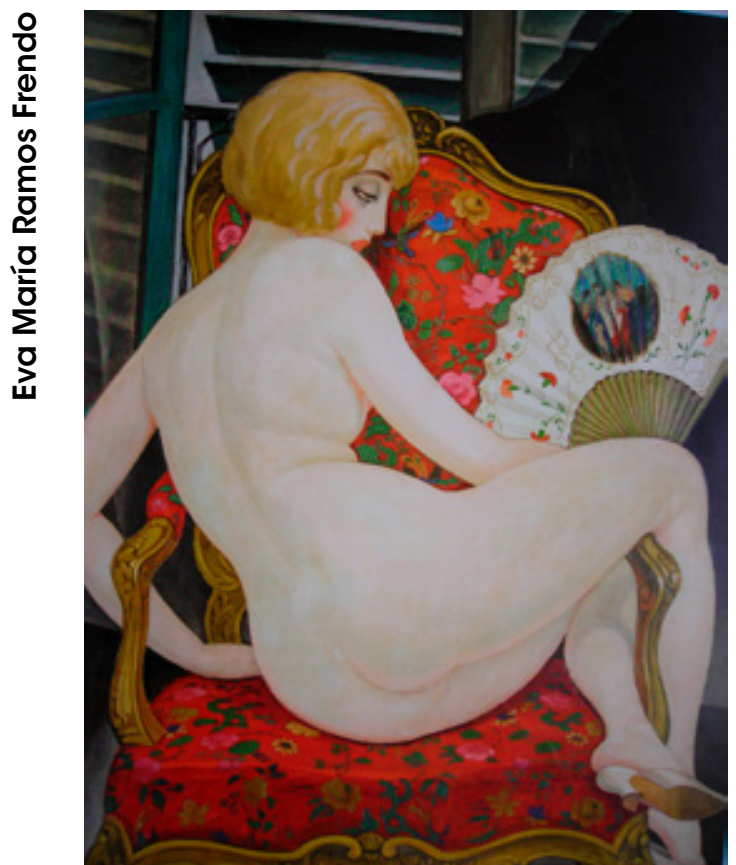

Fig. 11. In the Summer Heat (Lili), 1924, Gerda Wegener, pintura al óleo, $115 \times 87 \mathrm{~cm}$. Colección privada. En Gerda Wegener, ARKEN, 2015, p. 51. Copyright ARKEN

fue la vida del matrimonio, a raíz de surgir Lili, cuando fue habitual que Gerda alternara acompañada de esta en locales y eventos del París de la época, siendo presentada como una amiga. En The Aperitif (1928) ambas se disponen como mujeres modernas - el estereotipo conocido como flapper - que salen a los locales de moda sin necesidad de acompañante masculino, fuman, beben y se maquillan en público. En este caso, ambas están sentadas en la mesa de un local, mostrándose a Lili en primer plano que, al igual que el resto de retratadas de Gerda, se acompaña de flor, además de guantes, usuales en la indumentaria de Lili, y un cigarrillo con larga boquilla. Tras ella, el perfil de Gerda con sombrero cloché. Al fondo las cristaleras del local, a base de formas geometrizadas y repetitivas, se abren dejando ver la ciudad, el toldo del establecimiento con el nombre del local, a través de letras invertidas, y la gente que transita al exterior, con un aspecto que refleja la incidencia del cubismo y otras vanguardias en la obra de esta artista, como es habitual en el Art Déco. Cuando esta obra, junto con la titulada Femme a la Rose, fueron presentadas en el Salón

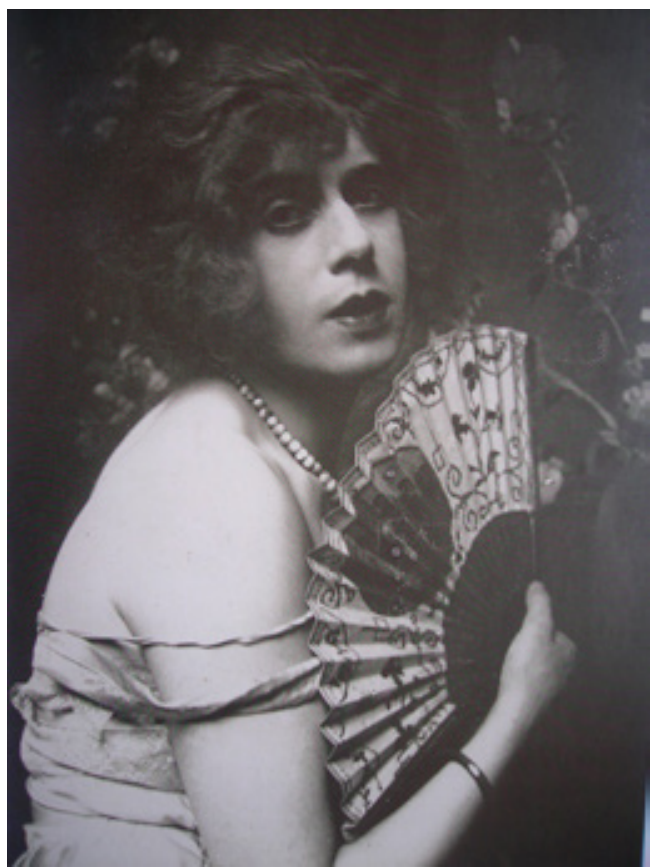

Fig. 12. Retrato fotográfico de Lili (1926), probablemente realizado por Gerda Wegener. Colección privada. En Gerda Wegener, ARKEN, 2015, p. 42. Copyright ARKEN

de Otoño de ese año, la crítica española las describió como "... de espíritu tan opuesto como lo son el candor y la malicia, y realizadas con acierto y agilidad sin igual" ${ }^{53}$. Estas palabras pueden deberse a que mientras Femme a la Rose mostraba a jóvenes dulces, vestidas de forma clásica, "con largas pestañas, cuerpos blancos"54, embelesadas ante la contemplación de unas flores, The Aperitif presentaba a Gerda y Lili como estereotipos de modernidad - fumando, bebiendo, con cabellos cortos, miradas descaradas y solas en un local de moda - hecho que pudo ser considerado de mayor peligro y malicia para la época y, además, ante la mentalidad más tradicional de los españoles. Existe una obra muy similar y de igual título, pero en la que tan solo aparece Lili.

No obstante, no siempre será Gerda la compañera de escena de Lili. En 1928 realiza un retrato en el que Lili aparece en compañía del marchante de arte Claude Lejeune, en la localidad de Beaugency. Esta obra plasma, igual que también podemos observar en fotografías de la época, su nuevo amor y futuro esposo, algo que su fallecimiento hizo imposible. 


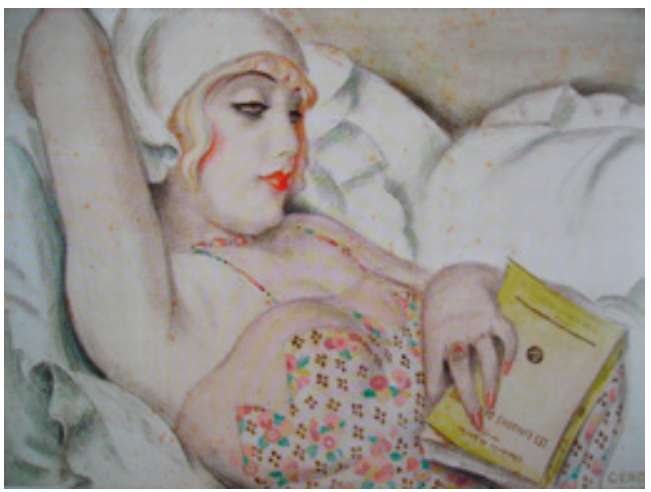

Fig. 13. The Siesta (Lili), 1922, Gerda Wegener, dibujo y acuarela sobre papel, $50 \times 60 \mathrm{~cm}$. Centro Pompidou, National Museum of Modern Art. En Gerda Wegener, ARKEN, 2015, p. 72. Copyright ARKEN

Dentro de los retratos grupales, entre los que destaca la figura de Lili, junto a Gerda y otras damas, destaca el titulado A Summerday, obra de gran formato que fue presentada en 1927 al Salón de los Independientes (fig. 14). Nos muestra una alegoría de las artes a través de la literatura, la música y la pintura55. En la escena, se representan a Lili y Einar en el mismo espacio, algo no habitual en las obras de Gerda. En primer plano se dispone a Lili desnuda, recostada ligeramente de espaldas, mientras vuelve de nuevo a sostener una rosa. Se encuentra flanqueada por otras dos damas, Elna Tegner - esposa de Rudolf Tegner que ameniza el momento tocando el acordeón (alegoría de la música), y la señora Guyot, que sostiene un libro (alegoría de la literatura). En segundo plano a la izquierda observamos a Einar - cual Velázquez en Las Meninas - retratando al grupo ante su caballete (alegoría de la pintura), mientras otra joven, cargada de flores, cierra el lado derecho de la composición. La escena vuelve a estar recorrida diagonalmente por los haces luminosos que geometrizan el ambiente, tan propios de Gerda y del Art Déco. Al fondo el paisaje de Beaugency, otro de los parajes más apreciados por la pareja y sus amistades.

También grupal y de gran formato, insertando en el mismo a Gerda y su perro, On the Banks of the Loire (The artists' colony at Beaugency) (1926) (fig. 15) nos muestra a un grupo de hombres y mujeres, del círculo bohemio con el que se relacionaban Gerda y Lili, que disfrutan al sol junto al río Loira a su paso por la citada localidad. Los

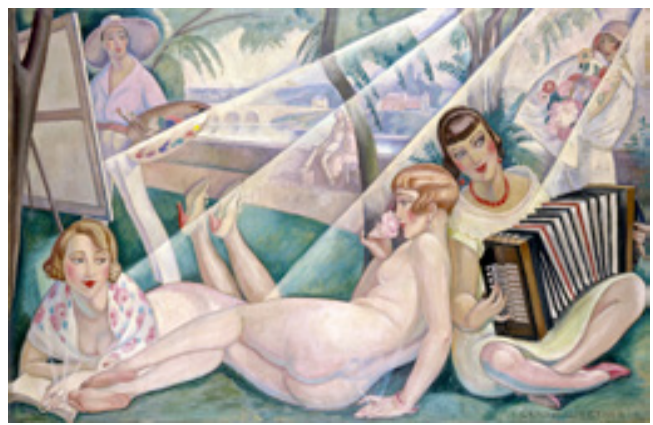

Fig. 14. A Summerday, 1927, Gerda Wegener, pintura al óleo, $130 \times 200 \mathrm{~cm}$. Colección privada. En http://uk.arken.dk/press/ gerda-wegener/. Copyright ARKEN

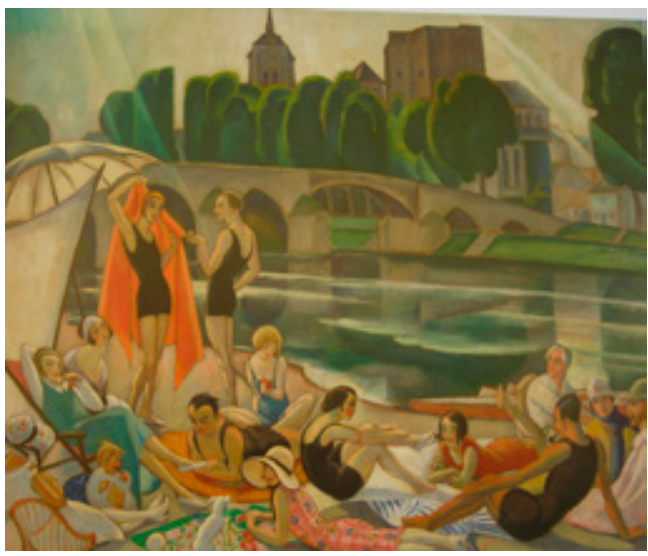

Fig. 15. On the Banks of the Loire (The artists' colony at Beaugency), 1926, Gerda Wegener, 109 x 129,3 cm. Colección privada. En Gerda Wegener, ARKEN, 2015, p. 27. Copyright ARKEN

artistas, algunos ataviados con bañadores y en posturas desenfadadas y relajadas, se disponen ante un paisaje que nos recuerda al Picasso del primer cubismo o a Cezanne, con ese predominio de tonalidades ocres y verdosas. En dicho escenario podemos observar el puente que cruza sobre el río, el castillo y la torre de la abadía de Notre Dame de dicha ciudad, una de las joyas del románico. Gerda, centralizando la escena en primer plano, se dispone boca abajo, protegida del sol con un sombrero de ala ancha. Otras mujeres, al igual que los hombres, se encuentran fumando, en esta ocasión en pipa, para demostrar su pertenencia a un grupo más inconformista y bohemio, al margen de muchos prejuicios sociales. La obra, expuesta en el Salón de los Independientes, fue considerada un pretexto por parte de Gerda 
Wegener para mostrarnos la delicadeza de su observación, la facilidad para componer y la forma seductora de sus dibujos ${ }^{56}$. Beaugency fue también objeto de los paisajes de Einar, incluyendo a Gerda en los mismos ${ }^{57}$. Junto a Capri, será otro de los lugares predilectos de la pareja y, por tanto, reflejados en sus obras.

\section{Conclusiones}

Tras lo expuesto - que es solo una parte de su labor como artista - se puede apreciar que nos encontramos, tal y como se adelantó, con una pionera para la época que le vio nacer. Su retratos no solo sirvieron para dar una imagen agradable y exaltadora de las damas de su época, mostrando a las mujeres a través de la visión de otra mujer, llenas de dulzura, candor y belleza, sino que fueron, sobre todo, el vehículo que dio a Lili la posibilidad de desenmascararse y exponerse al mundo de la manera que deseaba ser, consiguiendo camuflar su aspecto masculino y revelar su verdadero yo. Por otra parte, muchos de los retratos y autorretratos de Gerda se convierten en un vehículo para conocer su propia vida, su relación con Lili, los lugares por los que transitaron, sus amistades y la forma de afrontar su destino. Su obra se presenta como el relato de una singular relación de pareja - sobre todo para la época en que aconteció - y muestra a una creadora transgresora y valiente. Gerda supo construir al verdadero Einar, a Lili, la imagen con la que realmente se veía identificada. Pero, como se puede apreciar en este y otros estudios, además de artista, Gerda fue una mujer adelantada a su época y luchadora, que supo rivalizar y triunfar en un mundo mayormente ocupado por varones que debieron verse arrollados por esa mujer de gran carácter. El París de los años veinte la admiró y valoró, tal y como se desprende de los numerosos encargos que recibió a lo largo de su vida.

Con posterioridad a su fallecimiento, en 1940, fueron pocas las ocasiones en que sus compatrio- tas daneses se acordaron de ella, perdurando la tónica existente a lo largo de su vida ${ }^{58}$. En 1993 - comisariada por Mona Jensen - tuvo lugar una primera exhibición sobre su obra en The Women's Museum de Aarhus ${ }^{59}$. En 1999, el Øregaard Museum también realizó otra muestra - organizada por Lise Svanholm - que más tarde se trasladó a la Maison du Danemark de París ${ }^{60}$, capital donde sí ha existido un gran interés por investigar y difundir la obra de esta artista, trabajando facetas como el papel jugado durante la Primera Guerra Mundial ${ }^{61}$ o su trayectoria en París, en la que el historiador Frank Claustrat ha sido el máximo especialista. También Nueva York, en la Galería Leonard Fox, organizó en 2009 una muestra titulada Gerda Wegener: la Vie Parisienne.

Pero coincidiendo con las fechas del estreno de la película La Chica Danesa62, en Dinamarca se ha despertado el interés por la figura de esta artista, algo claramente evidenciado a raíz de la organización de una exposición retrospectiva de su obra en Arken, con un total de 178 piezas - 169 de Gerda y 9 de Einar -, comisariada por Andrea Rigg Karber y celebrada desde noviembre de 2015 hasta mayo de 2016, siendo más tarde ampliada al 8 de enero de 2017, lo que demuestra la gran aceptación de la muestra63. A raíz de la misma, la prensa danesa dejó constancia de que Gerda era un personaje casi desconocido en el panorama artístico danés del siglo XX, lo que se intentaba subsanar a través de dicha exposición. Aunque en el año 2000 Daniel Ebershoff publicó la novela en la que se ha basado el film para narrar la relación de esta pareja, ha sido su adaptación a la gran pantalla la que ha conseguido estimular, en toda Europa, una repentina curiosidad por conocer a Gerda Wegener. Por tanto, como exponíamos al comienzo de este trabajo, nuestro deseo es dar a conocer en España la obra de esta artista hasta hace poco totalmente desconocida y que ahora parece ser poco a poco recuperada. 


\section{NOTAS}

'Profesora Titular del departamento de Historia del Arte de la Universidad de Málaga. Este artículo recoge resultados de las investigaciones que se están desarrollando dentro del Proyecto I+D "Prácticas de subjetividad en las artes contemporáneas: recepción crítica y ficciones de la identidad desde la perspectiva de género" (ref. HAR201675662-P) financiado por el Ministerio de Economía y Competitividad.

2 Esta introducción biográfica, aunque con nuevas aportaciones en el presente trabajo, ya ha sido desarrollada en E. M. Ramos Frendo, "Las ilustraciones de la danesa Gerda Wegener (1884-1940) en el semanario francés La Baionnette. Un satírica visión femenina de la Primera Guerra Mundial", AACA, $n^{\circ} 34$, marzo 2016. No obstante, consideramos necesaria su presencia para poder comprender las obras analizadas.

${ }^{3}$ Los datos biográficos pueden ser contrastados a través del catálogo publicado en 2015 por Arken. A. Grubb Martinussen. "Biography" en Gerda Wegener, Arken, Ishoj, 2015, pp. 8185.

${ }^{4}$ A. Rigg Karber, "When a woman paints woman" en Gerda Wegener, op. cit., p. 14.

${ }^{5}$ F. Claustrat, "Nordic Writers and Artists in Paris before, during and after World War I", Avant-Garde Critical Studies, vol. 28, 2012, p. 130.

${ }^{6} \mathrm{H}$. Cossira, "Feue la Rotonde", Le Monde Illustré, 25/01/1936, p. 78.

${ }^{7}$ M. L. Stewart, Dressing Modern Frenchwomen. Marketing Haute Couture, 1919-1939, The Johns Hopkins University Press, Baltimore, 2008, p. 39.

${ }^{8} \mathrm{~J}$. Francés, "Salón de Humoristas contemporáneos: Helen Dryden", Buen Humor, 30/04/1922, p. 16.

${ }^{9}$ Scaramouche, "Le Salon de la Mode", Les Modes de la Femme de France, 26/03/1922, n 359, p. 9

10 "Les indiscrétions de L'Amousant", Le Journal Amusant, $\mathrm{n}^{\circ}$ 8, 28/07/1929, p. 14.

${ }^{11} \mathrm{G}$. Varenne, "L'art urbain et le mobilier au Salon d'Automne", Art et Décoration, t. XLIV, julio de 1923, p. 164.
${ }^{12} \mathrm{~J}$. Francés, "De Norte a Sur. Ante unos dibujos de Gerda Wegener", La Esfera, 05/08/1916, p. 29.

${ }^{13} \mathrm{lbid}$.

${ }^{14} \mathrm{P}$. Caizergues et $\mathrm{M}$. Décaudin (eds.), Apollinaire. Oeuvres en prose complètes, vol. II Paris, Gallimard, 1993, pp. 819-820.

${ }^{15}$ Montjoie! Numéro consacré à la Danse Contemporaine, $n^{\circ} 1-2$, janvierFévrier 1914, p. 17. Ilustración de Gerda Wegener representando a Valentine de Saint-Point.

16 "Les Lundis de "Montjoie!", Ibídem, p. 18. Se puede realizar un recorrido por muchos de los nombres de los/las artistas que participaban de estos encuentros.

${ }^{17}$ M. Pays, "Le Salon du Rire au Palais de Glace", Le Radical, 19/04/1913; M. Pays, "Le Vernissage du Salon des Humoristes", Le Radical, 18/04/1914, p. 2; G. Rémon, "Au Salon des Indépendants. Les secteurs étrangers", Le Radical, 11/02/1924; La Renaissance politique, litterraire, artistique, p. 6; Scaramouche, "Le Salon de la Mode", La Femme de France, p. 9; F. Ribadeau Dumas, "Le Vernissage du Salon des Indépendants", La Presse, 20-01-1929, p. 1.

18 H. Fontaine, "Croix-Rouge. Union des Femmes de France", Le Gaulois, 02/05/1915, p. 3. G. Davenay, "La Danoise", Le Figura, 02/05/1915, p. 1.

${ }^{19}$ Société des Artistes Indépendants. Catalogue 32 Exposition, Paris, 1921, p. 162; Société des Artistes Indépendants. Catalogue 33 Exposition, Paris, 1922, p. 181; Société des Artistes Indépendants. Catalogue $34^{a}$ Exposition, Paris, 1923, p. 256; Société des Artistes Indépendants. Catalogue $35^{a}$ Exposition, Paris, 1924, p. 253; Société des Artistes Indépendants. Catalogue $36^{a}$ Exposition, Paris, 1925, p. 314; Société des Artistes Indépendants. Catalogue $38^{a}$ Exposition, Paris, 1927, p. 332; Société des Artistes Indépendants. Catalogue $39^{a}$ Exposition, Paris, 1928, p. 382; Société des Artistes Indépendants. Catalogue $40^{a}$ Exposition, Paris, 1929, p. 370 y Société des Artistes Indépendants. Catalogue $41^{a}$ Exposition, Paris, 1930, p. 370.

20 "Les Expositions. Galeries particulières", Les Nouvelles littéraires, artistiques et scientifiques, 24/03/1923, p. 2. "Les Expositions", Le Bulletin de la vie artistique, 01/04/1923, p. 155.

${ }^{21}$ T. S., "Le Salon des Humoristes", Le Temps, 12/03/1922, p. 4. Ch. Fegdal, "Au Salón des Humoristes", La Revue des Beaux-Arts, 03/1925, p. 6.

${ }^{22} \mathrm{C}$. Le Senne, "Au Salón de Otoño", Le Menestrel, 02/10/1925, p. 405. S. Ed, "Au Salón de Otoño", Journal des débats politiques et littéraires, 31/10/1924, p. 3.

${ }^{23}$ Ch. Fegdal, "Chrónique D'Art Moderne", La Revue des Beaux-Arts, 15/03/1926, p. 6.

${ }^{24}$ G. Kahn, "Le Nouveau Salón", Mercure de France, 15/05/1928, p. 210.

25 P. Sentenac, "Le Lap et les artistas", La Renaissance politique, litteraire, artistique, 23/06/1928, p. 6.

${ }^{26}$ Ch. Bussy, "Arts Décoratifs", Les Dimanches de la femme, 13/10/1929, p. 3.

27 "Un Tournoi International. Sa grâce miss Hongrie triomphe, en beauté, au championnat d'Europe", L'Echo Sportif de I' Afrique du Nord, 15/02/1929, p. 4. También la prensa española se hizo eco de este certamen, La Voz, 08/02/1929, p. 8

${ }^{28} \mathrm{~N}$. Hoyer, \& L. Elbe, Man into de woman: the first sex change, a portrait of Lili Elbe: the true and remarkable trasformation of the painter Einar Wegener, Blue Boat Books, London, 1933.

29 J. Ames, (Ed.), Sexual Metamorphosis: An Anthology of Transsexual Memoirs, A Vintage Boosk Original, New York, 2005, p. 16.

${ }^{30} \mathrm{I}$. Christensen, "Early 20th-Century Danish Women Artists in Linght of De Beauvoir's "The Second Sex" ", Woman's Art Journal, vol. 9, n 1, pp. 10-15.

${ }^{31}$ Sobre el proceso de reasignación quirúrgica de género de Einar Wegener para convertirse en Lili Elbe consultar J. Nero, Hannah Höch, Til Brugman, Lesbianism, and Weimar Sexual Subculture, Department of Art History and Art Case Western Reserve University, 2013, pp. 273-280.

32 "Le peintre Wegnere est-il hermaphrodite?", Comoedia, 02/03/1931, p. 1.

${ }^{33} \mathrm{~J}$. Ames (Ed.), Op. cit., p. 26.

${ }^{34}$ T. Theophano, "Elbe, Lili" en C. J. Summers, (Ed.), The Queer Encyclo- 
pedia of the Visual Arts, Cleis, San Francisco, 2004, p. 109. T. Armstrong, Modernism, Technology and the Body, Cambridge University Press, Cambridge, 1998, p. 172-173.

${ }^{35} \mathrm{M}$. Theliol, (21 de mayo de 2013). "L'Essor des Sociétés Artistiques au Maroc durant le Protectorat Français (1922-1956)", Marocmediterranee. [Consulta: 17/10/2015]. http:// marocmediterranee.blogspot.com. es/2013/05/lessor-des-societes-artistiques-au.html.

${ }^{36}$ P. Henry, "L'Exposition PortaMammeri à Marrakech", L'Afrique du Nord Illustree, 27/01/1934, p. 5.

37 "Le vernissage de la 48 Exposition de la Société des artistas indépendants a lieu aujourd'hui a u pavillon des Salóns", Le Matin, 05/03/1937, p. 5.

${ }^{38} \mathrm{~T}$. Weirup, (30 de agosto de 2015). "Genopdaget. Kvinde kend din krop", Berlingske: Kultur, 30/08/2015. [Consulta: 12/11/2015] http:// www.b.dk/kultur/kvinde-kend-din-krop

${ }^{39} \mathrm{La}$ exposición celebrada en Arken desde noviembre de 2015 a enero de 2017 ha sido una gran oportunidad de conocer muchas de las obras que se encuentran depositadas en colecciones privadas y, por tanto, no accesibles al público.

40 "Gerda Wegener", Arken Museum of Moderna Art, 7 November 2015 to 16 May 2016. [Consulta: 12/11/2015] http://www.arken.dk/udstilling/gerda-wegener/.

41 Mercure de France, 12-1929, p. 418; G. Kahn, "Le Nouveau Salon", Mercure de France, 15/05/1928, p. 210.

${ }^{42}$ A. G., Linares, "París. Salón de Otoño", La Esfera, 22/12/1928, p. 10.

${ }^{43} \mathrm{~A}$. Rigg Karber, "When a woman paints woman", Gerda Wegener. Ishoj: Arken, 2015, p. 26.

${ }^{44} \mathrm{~A}$. Weis, Paris era mujer. Retratos de la orilla izquierda del Sena. Egales, Madrid-Barcelona, 2014.

45 B. Háger, "À propos de Carina Ari (1897-1970)". [Consulta 01/10/2015]. http://carina.se/aboutcarina-ari_fr.html.

46 "Le Salón de Otoño 1923", (1 de enero de 1924). Vogue. vol. 5, n 1 , 01/01/1924, p. 42.
${ }^{47}$ R. Lee, "Georgia O'Keeffe, Cheney Brothers, and the Relationship between Art and Industry in the 1920s" en Seeing High \& Low: Representin Social Conflict in American Visual Culture ( $P$. Johnston, ed.), University of California Press., Los Ángeles, 2006, pp. 235-236.

${ }^{48} \mathrm{~A}$. Rigg Karber, "When a woman paints woman" en Gerda Wegener, Arken, Ishoj, 2015, pp. 13-36.

${ }^{49}$ Se trata de On de Way to Anacapri (1922). Esta obra fue exhibida dos años más tarde, en 1924, en Le Musée du Luxembourg, espacio donde se exponían las obras de los artistas de las escuelas extranjeras en París, dentro de la sección destinada a las aportaciones danesas. Cfr. Le Musée du Luxembourg. Peintures pastels, aquarelles et dessins des écoles étrangères. París, 1924, p. 43.

50 Société des Artistes Indépendants. Catalogue $34^{a}$ Exposition, Paris, 1923, p. 256

${ }^{51}$ Obra subastada el 20 de febrero de 2013 en el Hôtel Drouot y que salió con un precio de partida de 2000/3000 $€$. Cfr. J. C. Renard, Catalogue de vente, n ${ }^{\circ} 72$, Paris, 20/02/2013, p. 26.

${ }^{52}$ Obra adquirida, en 1932, por la Fundación Nacional de Arte Contemporáneo de París. Actualmente expuesta en el Centre Pompidou de París.

53 A. G. Linares, "París. Salón de Otoño", La Esfera, 22/12/1928, p. 10.

${ }^{54} \mathrm{~L}$. Paillard, "Au Salon des Indépendants qui réunit près de 5.000 oeuvres", Le Petit journal, 20/01/1928, p. 2

${ }^{55} \mathrm{~F}$. Claustrat, "Copenhague: Gerda Wegener à l'avant-garde LGTB", Connaissance des Arts, 16/11/2015. [Consulta: 20/11/2015]. https://www. connaissancedesarts.com/peinture-etsculpture/copenhague \%E2\%80\%89gerda-wegener-a-lavant-gardelgbt-1132734/].

${ }^{56} \mathrm{Ch}$. Fegdal, "Salon des Indépendants", La Revue des Beaux-Arts, $n^{\circ}$ 450, 15/04/1926, p. 3.

${ }^{57} \mathrm{~A}$. Rigg Karber, "When a woman paints woman" en Gerda Wegener, Arken, Ishoj, 2015, p. 21.

${ }^{58}$ Mientras el Estado Francés adquirió en vida de la artista tres obras para el museo del Louvre, hoy día expuestas en el Centre Pompidou de París, los mu- seos daneses no se hicieron con ninguno de sus trabajos. Solo tras su muerte se compraron y mostraron algunas de sus obras, en número sumamente escaso, por parte de museos de su país natal. Solo los coleccionistas privados valoraron a la artista y hoy día cuentan con sus creaciones.

${ }^{59} \mathrm{M}$. Jensen, Gerda Wegener, Aarhus Kwindemuseet i Danmark, 1993.

${ }^{60}$ L. Svanholm, F. Claustrat \& M. Jensen, Gerda Wegener, portraitiste danoise du Paris des années 20, Maison du Danemark, Paris, 2000.

${ }^{61} \mathrm{~N}$. H. Zmelty, "Une voix singulière au coeur de la Grande Guerre: Gerda Wegener", 5 "Troisième sexe" et décembre 2014, Bordeaux, Ahténée Père Joseph Wrésinsky, Organisée par la Societé des amis du Musée des Beaux Arts de Bordeaux. [Consulta: 09/07/2015]. http://amis-musees-bordeaux.com/events/une-voix-singuliereau-coeur-de-la-grande-guerre-gerdawegener-nicholas-henri-zmelty/. Este autor, especializado en las ilustraciones de revistas francesas y carteles, ha trabajado recientemente sobre esta artista en las Jornadas de Estudios "Les intermédiaires II. "Troisième sexe» et paradigme féminin dans la modernité artistique (1900-1930)" que fueron organizadas por Marcella Lista y Pascal Rousseau en la Universidad de París, el 30 de septiembre de 2015. [Consulta: 05/11/2015] http://blog.apahau. org/journee-detudes-les-intermediaires-ii-troisieme-sexe-et-paradigmefeminin-dans-la-modernite-artistique1900-1930-paris-30-septembre-2015/.

${ }^{62}$ Película dirigida por Tom Hooper y protagonizada por Eddie Redmayne (Einar/Lili) y Alicia Vikander (Gerda) que se estrenó el 27 de noviembre de 2015. La actriz Alicia Vikander, que interpretaba el papel de Gerda Wegener, se alzó con el Oscar a la mejor actriz de reparto. A. Messeguer, "Alicia Vikander se alza con el Oscar a la mejor actriz de reparto", La Vanguardia, 29/02/2016. [Consulta: 01/11/2016]. http://www.lavanguardia. com/cine/20160216/302208144341/ alicia-vikander.html.

${ }^{63}$ Gerda Wegener, ARKEN, [Consulta: 15/11/2015]. http://www.arken. dk/udstilling/gerda-wegener/ 


\section{REFERENCIAS}

Ames, Jonanthan, ed. 2005. Sexual Metamorphosis: An Anthology of Transsexual Memoirs. New York: A Vintage Boosk Original.

Armstrong, Tim. 1998. Modernism, Technology and the Body. Cambridge: Cambridge University Press.

Blaszczyk, Regina Lee. 2006. "The Colors of Modernism: Georgia O'Keeffe, Cheney Brothers, and the Relationship between Art and Industry in the 1920s." In Seeing High \& Low: Representin Social Conflict in American Visual Culture, edited by Patracia Johnston, 228-246. Berkeley: University of California Press.

Caizergues, Pierre, and Michel Décaudin, eds. 1993 Apollinaire. Oeuvres en prose complètes, vol. II. Paris: Gallimard.

Claustrat, Frank. 2000. Gerda Wegener, portraitiste danoise du Paris des années 20, Paris: Maison du Danemark.

Claustrat, Frank. 2012. "Nordic Writers and Artists in Paris before, during and after World War I." Avant-Garde Critical Studies 28: 129-148.

Claustrat, Frank. 2015. "Copenhague: Gerda Wegener à l'avant-garde LGTB." Connaissance des Arts. Accessed November 16, 2015. https:// www.connaissancedesarts.com/peinture-etsculpture/copenhague\%E2\% $80 \% 89$-gerdawegener-a-lavant-garde-lgbt-1132734/.

Christensen, Inga. 1988. "Early 20th-Century Danish Women Artists in Linght of De Beauvoir's 'The Second Sex'. ", Woman's Art Journal 9, no. 1: 10-15. https://doi.org/10.2307/1358357

Grubb Martinussen, Amalie. 2015. "Biography." In Gerda Wegener, edited by Crhistian Gether, Stine Hoholt, Andrea Rygg Karberg, and Amalie Grubb Martinussen, 81-85. Ishoj: Arken Museum of Modern Art.

Hoyer, Niels. 1933. Man into de woman: the first sex change, a portrait of Lili Elbe: the true and remarkable trasformation of the painter Einar Wegener. London: Blue Boat Books.

Jensen, Mona. 1993. Gerda Wegener, Arhus: Kwindemuseet i Danmark, 1993.

Nero, Julie. 2013. "Hannah Höch, Til Brugman, Lesbianism, and Weimar Sexual Subculture." PhD diss., Department of Art History and Art. Case Western Reserve University.

Ramos Frendo, Eva M. 2016. “Las ilustraciones de la danesa Gerda Wegener (1884-1940) en el semanario francés La Baionnette. Una satírica visión femenina de la Primera Guerra Mundial." AACA, no. 34. http://www. aacadigital. com/contenido.php?idarticulo=1192.

Rygg Karberg, Andrea. 2015. "When a woman paints woman." In Gerda Wegener, edited by Crhistian Gether, Stine Hoholt, Andrea Rygg Karberg, and Amalie Grubb Martinussen, 1339. Ishoj: Arken Museum of Modern Art.

Stewart, Mary Lynn. 2008. Dressing Modern Frenchwomen. Marketing Haute Couture, 1919-1939. Baltimore: The Johns Hopkins University Press.

Theliol, Mylène. 2013. “L’Essor des Sociétés Artistiques au Maroc durant le Protectorat Français (1922-1956)." Marocmediterranee. Accessed October 17, 2015. http://marocmediterranee. blogspot.com.es/2013/05/lessor-des-societesartistiques-au.html.

Theophano, Teresa. 2004. "Elbe, Lili." In The Queer Encyclopedia of the Visual Arts, edited by Claude Summers, 109. San Francisco: Cleis.

Weirup, Torben. 2015. “Genopdaget. Kvinde kend din krop." Berlingske: Kultur. Accessed August 30, 2015. http://www.b.dk/kultur/ kvinde-kend-din-krop.

Weis, Andrea. 2014. París era mujer. Retratos de la orilla izquierda del Sena. Madrid-Barcelona: Egales. 
